\title{
HISTÓRIA DA SEGUNDA ESCOLÁSTICA PENINSULAR NO AMBIENTE UNIVERSITÁRIO LUSITANO: UMA REFLEXÃO SOBRE AS CONCEPÇÕES JURÍDICO-POLÍTICAS DO DOUTOR MARTÍN DE AZPILCUETA NAVARRO
}

\author{
PENINSULAR SECOND SCHOLASTIC HISTORY IN THE LUSITANIAN \\ UNIVERSITYS ENVIRONMENT: A REFLECTION ABOUT THE DOCTOR \\ MARTÍN DE AZPILCUETA NAVARROS LEGAL AND POLITICAL CONCEPTS
}

${ }^{1}$ Fábio Fidelis de Oliveira

\section{RESUMO}

As ideias jurídicas e políticas da Segunda Escolástica Peninsular foram estabelecidas no território espanhol e português em um grande câmbio de docentes e concepções acadêmicas desenvolvidas pelos dois reinos. Nesse ambiente, destacamos a atuação do canonista Martín de Azpilcueta Navarro como elemento de ligação entre as teses estabelecidas pela Escola de Salamanca e as ideias desdobradas no ambiente português a partir da Universidade de Coimbra. O presente artigo busca apontar para os elementos trabalhados pelo Doutor Navarro a partir das obras de grandes expoentes da escolástica renovada em sua primeira fase de desenvolvimento, como no caso dos postulados defendidos pelo líder inconteste do movimento, o dominicano Francisco de Vitória.

Palavras-chave: Ideias jurídicas, Pensamento político, Segunda escolástica, Universidade de coimbra, Doutor navarro

\begin{abstract}
The Peninsular Second Scholastics political ideas were established on spanish and portuguese territories in a large exchange of professors and academic concepts developed in these two kingdoms. In this environment, we highlight the work of the canonist Martin de Azpilcueta Navarro as a connecting element between the theses established by the "School of Salamanca" and the ideas developed in the portuguese atmosphere from the University of Coimbra. This article seeks to point to the elements developed by Doctor Navarro from the works of the great exponents of scholastic renewed in its first phase of development, as in the case of the postulates defended by the undisputed leader of the movement, the dominican Francisco de Vitoria.
\end{abstract}

Keywords: Legal ideas, Political thought, Second scholastic, University of coimbra, Doctor navarro

\footnotetext{
${ }^{1}$ Mestre em Ciências Sociais pela Universidade Federal do Rio Grande do Norte - UFRN, Caicó - RN (Brasil). Professor do Centro Universitário do Rio Grande do Norte - UNI-RN, Tirol - RN (Brasil).

E-mail: fabiofabelix@yahoo.com.br
} 


\section{INTRODUÇÃO}

Os questionamentos expostos nas teses jurídicas e políticas próprias à renovação da Escolástica no século XVI eram apresentados em um claro posicionamento crítico aquilo que se estabelecia pelos caminhos da modernidade. Novas reflexões sobre a mecânica do poder viriam a lume através do contacto com as outras realidades culturais descortinadas pelas conquistas marítimas.

Neste novo mundo a tradição europeia seria defrontada com as indagações naturais sobre as atividades de colonização em regiões já marcadas por redes políticas autóctones. As reflexões jurídicas anteriores não apresentavam referenciais suficientes para a abordagem das inusitadas questões nascidas, seja na própria Europa ou nos novos territórios descobertos.

Dentre essas questões podemos destacar o problema da legitimação do domínio europeu ultramarino, do estatuto jurídico a se atribuir aos povos indígenas e dos pontos envolvendo o conceito e entendimento da chamada "guerra justa", também deve ser ressaltado o impacto da Reforma Protestante e a consequente reação nos desdobramentos do Concílio de Trento, a partir das novas diretrizes doutrinárias destinadas a reestruturar os alicerces políticos eclesiásticos com clara influência no campo secular.

Nesse período, o próprio Estado surgia como nova e específica estrutura política e demandava necessária renovação no que diz respeito às teorias a ele relacionadas. Assim, a própria reflexão política e, consequentemente, jurídica buscava adaptação aos novos desafios lançados à atuação do ente estatal, defrontado com a necessidade de suporte e legitimação frente às questões até então nunca antes refletidas, como aquelas que buscamos elencar no parágrafo anterior.

Diante dessas questões é que surge, desenvolvida na Península Ibérica a chamada Segunda Escolástica, Neoescolástica ou Escola Teológico-jurídica Peninsular, conforme as variadas titulações atribuídas a essa corrente de renovação tomista. Uma vez desenvolvida entre intensos câmbios teóricos entre Portugal e Espanha, podemos falar da formação de uma única escola e não de um pensamento autônomo lusitano ou espanhol.

António Truyol y Serra (1995, p. 60) considerou a "segunda escolástica" presente em duas das correntes teóricas dos "homens da igreja e docentes" que atuaram na formação dos clássicos do "Direito das Gentes". Segundo o autor, essas duas correntes - ao lado de uma terceira formada por romanistas e canonistas - seriam aquelas relacionadas com a 
ordem de São Domingos e à Companhia de Jesus, onde "prevalece o ponto de vista da Teologia Moral e do Direito Natural" constituiriam "o grosso do que se chamou "Segunda Escolástica” ou ainda a neo-escolástica do Renascimento e do Barroco, uma escolástica renovada em contacto com o humanismo, e que, a partir da Europa mediterrânea, se alargou á sombra da Contra-Reforma”.

Nesse grande panorama, importa consideramos as contribuições lusitanas prestadas no desdobrar das teses do movimento em questão. Nesse sentido, buscaremos compreender as principais ideias do Doutor Navarro, importante canonista (portanto, vinculado aos estudos jurídicos) primeiramente vinculado à Universidade de Salamanca e que viria terminar sua atividade docente na Universidade recentemente fixada na cidade de Coimbra.

Necessário destacar que a canonística ocupava lugar de destaque frente as preocupações jurídicas tipicamente moralizadoras que no período eram desenvolvidas no cursos universitários de leis e cânones, ambos considerados estudos de direito. Assim, ao lado da faculdade de artes (preparatória para os demais cursos) de medicina e de teologia, o conhecimento jurídico assim estruturado vinha a compor o grande quadro da universidade europeia desde a sua origem.

O Doutor Navarro, usualmente associado às prédicas morais constantes em seu "Manual de Confessores e Penintentes" bem como às considerações da canonística lançadas à economia, como na obra "Comentário Resolutório de Câmbios", comporta ainda um olhar mais detido sobre as principais linhas que inspiraram suas contribuições quanto aos questionamentos jurídico-políticos próprios da "Escola de Salamanca".

Noutro ângulo, podemos enxergar a questão também relacionada ao entendimento do "espírito" da fundação da Universidade de Coimbra que, como sabemos, contou com a colaboração do Doutor Navarro através da sua transferência da Universidade de Salamanca para assumir uma cátedra de Cânones na academia lusitana.

Aqui, nos chama atenção uma abordagem metodológica não interessada em enfocar tão somente a individualidade de certos pensadores, mas sim uma aproximação da história de suas ideias como a remontar, a partir dessas questões, uma visualização do período em que estava inserida, também no plano prático, a realidade política da sociedade que se pretende estudar (SKINNER, 2005. p.165).

Sobre a questão do enfoque metodológico, Martim de Albuquerque (2012, p. 20) chegou a destacar que tanto "a história institucional ou factual, como a história das doutrinas ou das ideias (se se quiser, lato sensu, a história do pensamento político) são 
apenas vertentes compreensivas ou interpretativas da história global, integral, plena, é lícito ao investigador eleger preferencialmente uma abordagem determinada".

Através deste ponto de vista, procuraremos enquadrar alguns elementos para uma caminho das ideias políticas relacionadas com o período delimitado para o presente estudo, período em que cremos ser possível identificar uma específica linha teórica de continuiade em uma primeira etapa de laços estabelecidos entre os dois reinos ibéricos.

Nesse sentido, para lançarmos um primeiro olhar para as contribuições do professor de Navarra quanto ao universo acima delimitado, devemos estabelecer alguns instantes de análise sobre as matrizes do seu desenvolvimento intelectual e, sobretudo, quanto aos elementos de vinculação teórica atuantes em sua docência.

\section{A SEGUNDA ESCOLÁSTICA PENINSULAR}

O Professor Martim de Albuquerque (1969, p. 883) utiliza a nomenclatura "Escola Peninsular", justamente para ressaltar a noção de uma unidade ideológica em Portugal e em Espanha, inclusive ao considerar que o que se aborda das reflexões dos teólogos espanhóis do século do ouro se aplica, mutatis mutandis a Portugal.

Para o referido professor, o ponto de vista do aristotelismo, uma vez recepcionado em Portugal desde o século $\mathrm{XIV}^{1}$, não sofrera mitigação nos dois séculos seguintes visto que os "tratadistas peninsulares" do século XVI lecionaram em universidades de Portugal e, segundo a expressão utilizada em seu estudo sobre o poder político no período, estão eles “indissoluvelmente ligados à cultura portuguesa" (ALBUQUERQUE, s.d, p.267).

Mario Júlio de Almeida Costa (2002, p. 343), conferindo destaque ao fato de que também participavam no movimento vários pensadores portugueses de vulto, fazendo circular autores e ideias entre os dois países considera que "não parece excessivo, portanto, falar-se numa Escola Peninsular de Direito Natural. Que teria repercussões na Europa transpirenaica".

\footnotetext{
1 Desde as ideias de Álvaro Pais, encontramos o tratamento dispensado à tese aristotélica na ambiência da cultura portuguesa.
} 
Margarida Seixas (1999, p.9) observou que a utilização preferencial em seu trabalho, dentre as variadas terminologias atribuídas tais quais "Neo-Escolástica", "Escola Teológico-Jurídica Peninsular", "Segunda Escolástica" e "Escola Espanhola de Direito Natural e das Gentes", seria a primeira e a terceira por considerá-las as mais sintéticas e claras.

Assim, a segunda escolástica definiu sua presença como um esforço de retorno ao aspecto chave do tomismo, agora projetado para as necessidades específicas do período, atuando como uma face das respostas à crise do pensamento teológico medieval, não em regime de ruptura, mas de resignificação da própria tradição.

Segundo Mário Júlio da Costa (2002, p.343), “após certo declínio verificado pelos fins da Idade Média" as questões levantadas em pleno século XVI representariam uma verdadeira "tendência para o retorno à reflexão direta do tomismo originário". Noutro sentido, a resposta elaborada pelo pensamento humanista emergente, diferente do caminho neoescolástico, primava pela contestação direta em regime de clara ruptura com as construções teóricas medievais, percebidas como equívocas e obsoletas.

O Renascimento, desenvolvido na península Ibérica entre o século XV e as primeiras décadas do século XVII, elaborou, na expressão de Pedro Calafate (2001, p. 24) "três grandes programas culturais": a Escolástica, o Humanismo e a Cultura de expansão. Essa reação aos antigos modelos esboçou nas expressões da Escola Peninsular e do Humanismo opções que valorizaram, sobretudo, o cultivo da experiência como válvula mestra para a adequação às novas questões, tão próprias à modernidade.

Entretanto, se o humanismo demonstrou ampla penetrabilidade como expressão do renascimento além dos Pirineus, a Segunda Escolástica deitou profundas raízes em território peninsular. No Humanismo identificamos as primícias do ponto de vista jusracionalista que logrou êxito e ampla divulgação através da figura de Erasmo e outros expoentes, contudo, na Escola Hispânica percebemos uma reação lastreada pela própria tradição católico-romana.

O chamado "Erasmismo", ao penetrar em território português nos grandes centros de estudos universitários do período enfocado como objeto do presente estudo, como o Colégio das Artes de Coimbra era visto, como um ponto de vista com sabor de heresia.

Interessante percebermos que, vitimado pela perseguição inquisitorial, a vertente humanista encabeçada por discípulos de Erasmo de Roterdã, fora extremamente prejudicada, levando a modificações no quadro docente das instituições de ensino que aqui 
serão abordadas como focos difusores das propostas da "Segunda Escolástica". Nesse sentido, o Colégio das Artes, passa às mãos da Ordem Inaciana que, nas etapas sequenciais, estabelecerá, em sintonia com o pensamento ibérico do período, uma vertente "humanística" renovadora do pensamento tomista.

Nesse sentido, nos lembra José de Pina Martins (1973, p. 161) que a Companhia de Jesus ao dominar o Colégio das artes a partir de 1555, dá por iniciada "uma nova era - e sob muitos aspectos culturalmente frutuosa e brilhante - para a Escola de Coimbra", fato que assinalaria a "morte do Erasmismo naquela Universidade". Apear do fato de que " os jesuítas mantiveram nos seus institutos uma tradição humanística que, em alguns aspectos não andava longe da que havia sido preconizada por Erasmo".

Não obstante, os teólogos peninsulares da época, preocupados em uma resposta alinhada com as novas perspectivas relacionadas à modernidade, representavam o setor privilegiado para a reflexão sobre as abordagens políticas e jurídicas de então, uma vez que temas como a origem e transmissão do poder e o consequente impacto dessas questões na esfera do direito eram preocupações para eles relacionadas com antigas linhagens teóricas, sobretudo no que diz respeito à matriz aristotélico-tomista.

Martim de Albuquerque (1998, p. 46) assim se expressa sobre a filiação e legado da escola objeto de nossos estudos destacando que a mesma "formulará a primeira teoria do poder, do Estado" visto como uma "nova entidade política" onde, através da metodologia do escolasticismo medieval, seriam colocadas as "grandes âncoras para o futuro".

Aqui, o direito natural surge como fruto de uma concepção teocêntrica que o encadeia em uma ampla rede relacionada com a Lei Eterna, a Lei Divina e a própria Lei Natural com seu impacto na chamada Lei Humana. Portanto, uma ordem superior se encontraria a presidir as instâncias inferiores no qual é destacado o próprio estado e as construções jurídicas, tudo isso existente em função da própria natureza gregária do homem, impressa pela divindade como característica desde o ato da criação.

Importante destacar que os teóricos relacionados com essa escola não se apresentam como meros atores na arena puramente especulativa, uma vez que atuavam tanto na área política própria às funções relacionadas com o labor eclesiástico, com as atividades docentes desenvolvidas nos grandes centros universitários do período, como também junto à política estadual onde, mais de uma vez, se apresentaram como conselheiros dos monarcas. 
Sobre esse ponto, a Espanha preferiu a convocação direta desses teóricos como conselheiros quanto aos movimentos da política estadual capazes de atingir a esfera moral do rei e, por conseguinte, do reino. Já em Portugal, encontramos a criação de instância jurídica específica para o trato desses mesmos assuntos, como foi o caso da Mesa da Consciência e Ordens, um dos tribunais régios bastante atuante na realidade quinhentista.

$\mathrm{Na}$ busca pelas origens remotas da escola de pensamento aqui abordada, podemos ressaltar, já no século XV, o pensamento dominicano de Tomás de Vio (Cardeal Caetano) e Francisco Silvestri, em um contexto pré tridentino e contra luterano com os comentários para a obra de Aristóteles e São Tomás, inclusive incentivados pelo Papa Leão XIII.

O Cardeal Caetano, no contexto de combate às teses luteranas, firmou posição em defesa da "razão natural" como elemento autônomo, destacando-se também como acirrado defensor da autoridade papal em sua obra "De auctoritate Papae et concilli utraque invicem comparata e Apologia tractatus de comparata auctoritate Papae et Concilli”.

Segundo Margarida Seixas (1999, p. 18) o Cardeal Caetano além de desenvolver seu pensamento sobre as obras de Aristóteles e as próprias sagradas escrituras com destacada "independência crítica" pode ser visto como um "autor de transição", cujas "aberturas seriam aproveitadas pelos hispânicos da Segunda escolástica".

Silvetri, ao seu turno, seguindo a mesma linha proposta pelo Cardeal, expôs em seu tratado "Apologia de convenientia institutorum Romanae Ecclesiae cum evangelica libertate" suas teses contrárias à reação luterana e atuou, da mesma maneira que Caetano, como veículo de mediação entre a escolástica abordada no século XIII e a renovação do tomismo desenvolvida três séculos depois.

Além dessas primeiras questões destacadas no panorama italiano, o contributo francês se faria sentir através da Universidade de Paris, centro de ensino no qual Francisco de Vitória, o principal expoente da escola peninsular, hauriria suas iniciais bases educacionais.

Em Paris encontramos uma das primeiras elaborações teóricas sobre a licitude da conquista dos novos territórios descobertos através da pena de John Mair, autor filiado ao ponto de vista nominalista e que discorreu sobre a licitude da ascendência europeia sobre os habitantes do novo mundo. ${ }^{2}$ 
2 Tese desenvolvida nos comentários a Pedro Lombardo. Para Mair essa possibilidade estaria relacionada com missão de difusão do cristianismo e pela noção de que os silvícolas seriam seres culturalmente inferiores àqueles que atuariam na pregação do Evangelho. 
$\mathrm{Na}$ fase sequencial (legatária dos primeiros esforços teóricos acima citados, ainda que reformulados em importantes aspectos) encontramos a formação e desenvolvimento da escola de maneira propriamente dita, já aqui em confronto mais amplo com as questões sociais e políticas surgidas no calor dos descobrimentos marítimos e todas as implicações jurídicas dele derivadas (legitimação da aquisição dos territórios, o trânsito pelos mares, novas questões econômicas e o trato com os povos das regiões descobertas).

A segunda escolástica, naquilo que podemos titular como sua primeira fase de desenvolvimento, teve como grandes centros de pensamento os ambientes acadêmicos das cidades de Salamanca e Alcalá. Identificamos, nesse panorama, alguns dos seus principais expoentes nas figuras de Bartolomé de Las Casas, Francisco de Vitória e Domingos de Soto.

António Truyol y Serra (1995, p. 59), ao destacar a especificidade desta etapa do pensamento da escolástica renovada no ambiente espanhol, relacionou os referidos juristasteólogos com o início das preocupações políticas e jurídicas no que diz respeito a um direito de base internacional, tendo em mente que "os problemas postos pelo descobrimento e a conquista do Novo Mundo não podiam deixar de provocar o mais vivo interesse". Tais questões tomariam por base uma teoria iniciada com a discussão "dos títulos que poderiam considerar para a justificação da sua incorporação na Coroa de Castela". Estas ocorrências teriam contribuído para que a reflexão teológica e jurídica alargasse suas perspectivas para a formação de uma "teoria da comunidade internacional e da sua ordem jurídica tanto à paz quanto à guerra”.

Em Salamanca, como importante foco da renovação do pensamento escolástico, emergia o Convento de Santo Estevão, como núcleo organizado pelos esforços dominicanos que, inclusive, forneceria à Universidade estabelecida na mesma cidade alguns dos seus mais destacados professores.

Como postulado básico dessa fase de desenvolvimento da escola citamos a concepção, relacionada com a origem e natureza do poder, que o mesmo residiria em última análise, junto à própria comunidade. Por esta concepção o poder viria de Deus diretamente para a estrutura comunitária, em razão dos próprios homens (e, por derivação,

também a própria comunidade de homens) disporem do elemento político em sua constituição natural. 
Estaria assegurada, através deste entendimento, a origem do poder em Deus ${ }^{3}$, contudo, há um claro afastamento de qualquer pretensão de transmissões diretas deste poder ao soberano. O entendimento o novo escolasticismo claramente destaca a via indireta pela qual os monarcas assumiriam o exercício do poder.

A defesa do clamado "direito divino dos reis" não lograria acolhimento nas proposições dos autores da Segunda Escolástica e merece o devido destaque, ainda que com as devido cuidado quanto às limitações teóricas do período, que a visão de uma origem claramente democrática do poder, tem a sua clara marca nos pioneiros teóricos peninsulares, ainda que os mesmo não facultassem maiores desenvolvimentos para a ideia de um exercício também democrático.

Sobre a temática do poder, Francisco de Vitória, o líder inconteste da segunda escolástica em suas origens e na influência também estabelecida na fase posterior, destacou o afastamento do poder exercido temporalmente das pretensões universalistas tanto do papado quanto da ideia "imperial", uma vez que apontava a própria origem e proveito da força política como inerente a essa mesma comunidade.

Para Vitória ${ }^{4}$ e os seus sequenciais seguidores, para além do impacto dessas ideias junto à negação de uma justificação absolutista a evocar o direito divino dos reis, encontrase também a negação de uma possível concentração dos poderes temporais por parte do pontífice, tese prontamente afastada com a ideia de uma incidência temporal apenas indireta e sempre relacionada com o comprometimento de questões de fundo espiritual, essas sim próprias e naturais ao campo de ingerência papal.

Tal questão, presente em uma antiga tradição de debates acerca das relações e limites (ou ausência deles) entre a esfera espiritual e temporal remonta ao ponto de vista de Tomás de Aquino, em suas preocupações acerca das organizações políticas, vistas por ele como filhas da natureza humana e, portanto, obras que não estariam relacionadas com a imperfeição ou “queda”, segundo apontava a própria concepção patrística.

Ao assumir uma postura mais otimista diante das organizações políticas temporais, o Aquinate lança as bases para o entendimento de uma possível visão de

\footnotetext{
3 Segundo o postulado "nulla potestas nisi a Deo". A concepção de uma transmissão do poder, segundo os ditames teocêntrico próprios ao pensamento do Aquinate, é aqui renovada, mesmo que em flagrante oposição aos anseios imperialistas desenvolvidos pelos Reinos Peninsulares do período.

4 Sobre a temática do poder, destacam-se as relações "De potestate Ecclesiae prior", "De potestate Ecclesiae posterior" e "De potestate Papae 
equilíbrio entre essa ordem e aquela de origem espiritual, contudo, segue a mesma linha agostiniana quando não se furta em considerar que a estrutura política "estadual" deve estar voltada para a condução do homem ao supremo bem. ${ }^{5}$

Neste ponto, os autores da segunda escolástica buscaram destacar com bastante ênfase a concepção de duas ordens distintas, caminhando pelo percurso teórico de Tomás de Aquino na defesa de uma origem natural do poder e, por consequência, na noção de que ele repousa na própria comunidade.

Outro ponto sensivelmente ligado às percepções anteriormente descritas tem relação com a questão indígena ${ }^{6}$, uma vez que abordou as possibilidades "legitimas" de ocupação dos territórios americanos na abordagem de uma clara "liberdade política" atribuída aos habitantes das terras descobertas. Para Vitória os índios deveriam ser vistos como claros proprietários dos territórios, fato que apenas autorizaria uma intervenção dos estados europeus através da ocorrência de certas causas (títulos legítimos), quais sejam: ensejo de uma "intervenção humanitária"; permissão dos próprios índios; em caso de guerra justa, numa ação em apoio a um aliado e numa espécie de "tutela" à comunidade indígena que não pudesse se firmar em uma organização estável.

Sobre o Direito à guerra, na síntese de Truyol y Serra (1995, p. 63), Vitória "retoma a doutrina cristã tradicional do Bellum Justum, e desenvolve-a" uma vez que seria vista, enquanto justa, "pela sua necessidade, na medida em que for o único meio de reprimir a injustiça entre os povos", ou seja, nessa questão Vitória manteria sua posição filiada às "três condições clássicas da guerra justa: causa justa suficiente, autoridade legítima (o Estado como tal) e intenção reta".

Antes mesmo de vir a lume a relação de Vitória que abordou, de maneira mais detida, as implicações nos domínio do ultramar espanhol quando do contacto com os povos indígenas (De Indis), Soto já se alinhava ao seu pensamento através da relação "De Domínio”, redigida em 1534 embora naquela altura ainda inédita. Segundo Béltran de Heredia, Soto, nessa questão, faz uma clara "referência implícita" à relação "De potestate Ecclesiae” de Vitória. (Herédia, 1961, p. 252).

Os reflexos do pensamento de Vitória, verdadeiro líder teórico do que podemos nominar como "Escola de Salamanca" ainda se fariam sentir no ensino e defesa teórica de

\footnotetext{
5 Segundo a obra "De regno", onde encontramos a consideração acerca da direção com a qual o poder temporal deveria conduzir os homens, no destaque para a noção de que os homens manifestam a "precisão daquele cuidado espiritual" capaz de conduzi-lo ao "porto da salvação eterna". (Aquino, 1997, p. 27).

6 Sobre o tema, destaca-se a "relação" publicada pelo Fr. Francisco de Vitória no ano de 1539 com o título conhecido por "De indis".
} 
outros teólogos-juristas ou mesmo no campo especifico dos catedráticos da faculdade de leis, quais Gregório López, Fernando Vázquez de Menchaca, António Gómez e Juan de Orozco.

Em território dos juristas-teólogos, podemos destacar as figuras Diego de Covarrubias e Martín de Azplicueta Navarro, dois professores que caminham pelos mesmos passos até então aqui dispostos, constituindo-se o primeiro, na opinião de Luciano Pereña (1986, p.47), a terceira fonte mais importante depois de Vitória e Soto.

Quanto ao Doutor Navarro, que aqui tomamos como objeto específico de nossas análises, importante atentar para o devido enquadramento de sua atuação acadêmica como um traço de ligação entre as universidades de Salamanca e Coimbra, tendo em vista que o início de sua docência em Portugal foi estabelecido sob os auspícios de D. João III por ocasião da refundação da universidade que se transferia para a cidade do norte do país.

Nesse sentido a primeira contribuição da Universidade de Coimbra quanto às temáticas jurídicas e políticas pode ser enquadrada no mesmo rol de preocupação que visualizamos nos autores tradicionalmente vistos como pertencentes à chamada "Escola de Salamanca", uma vez que o Doutor Navarro e outros filhos intelectuais de Salamanca (como o professor Martín Ladesma) continuariam a estabelecer a disseminação das análises constantes no ensino dos autores pertencente a um primeiro ciclo da escolástica renovada.

Cumpre-nos aqui, para uma breve visualização da completude temporal da Segunda Escolástica Peninsular, destacamos como centros de pensamento relacionados com uma segunda fase a sequencial etapa de reflexões na Universidade de Coimbra e os iniciais trabalhos relacionados com o ensino na Universidade de Évora. Como os mais destacados representantes deste período citamos as personalidades de Francisco Suárez, com a sua importante atuação e produção coimbrã e Luís de Molina, com suas contribuições enquanto lente da Universidade de Évora. ${ }^{7}$

Nesta segunda fase, as principais preocupações estabelecidas pelos autores buscavam gravitação em portos mais afastados daqueles experimentados por professores como Francisco de Vitória, ou seja, contavam com certo distanciamento temporal do grande impacto produzido pelos descobrimentos e o clima político próprio ao período.

\footnotetext{
7 Como autores também ligados a essa fase citamos ainda, José de Acosta, Juan de Mariana, Pedro Fonseca, Pedro Simões, dentre outras personalidades tipicamente relacionadas com a ordem
} 
Se tomarmos como objeto de nossas análises o percurso teórico estabelecido entre Francisco de Vitória e Suárez, encontraremos cenários sociais e políticos diversos e com especificidades que atuaram em uma nova visão do legado tomista repassado aos professores de Coimbra e Évora, pelos esforços dos primitivos entendimentos dos mestres de Salamanca e Alcalá.

Paulo Merêa (s.d, p. 139-140), em louvável síntese, apontou as questões incidentes nesse trajeto atualizador tais como o chamado cisma protestante, a "dividir a cristandade em dois campos irreconciliáveis e desintegrando larga parte da Europa do seio da Igreja Universal", o "sonho imperialista de Carlos V" que encontrou a "resistência dos príncipes alemães", "na lógica do espírito da Reforma", o "incremento da monarquia absoluta como tipo de governo" e, de forma marcante durante boa parte da vida de Suárez, um perene clima de guerra civil desde o "extermínio oficial dos Hugenotes" à subida ao trono francês de Henrique IV e sua conversão ao catolicismo romano.

Há nos autores dessa segunda fase um marcado clima pós-tridentino, onde o destaque para a liberdade como elemento contrário a posturas deterministas se faz presente com grande ênfase. Noutro aspecto, pode ser observada também, uma clara progressão quanto aos postulados tomistas refletidos anteriormente. ${ }^{8}$

A ênfase no problema da liberdade constitui uma clara postura de reação às propostas deterministas lançadas pelas correntes da Reforma, questão bastante sensível nessa fase da Segunda Escolástica que corresponde, essencialmente, aos esforços católicos de defesa à difusão protestante dentro do ambiente acadêmico de reinos profundamente católico-romanos como Portugal e Espanha.

Não sem razão, também é perceptível uma postura de maior liberdade teórica no que diz respeito às reflexões de Tomás de Aquino, tendo em vista que é aprofundada, através do destaque conferido aos autores próprios dessa fase, mais ampla autonomia atribuída à ordem jurídica positiva, isso sem falarmos em rompimentos abruptos com aquilo que já marcava presença na fase precedente de desenvolvimento do pensamento peninsular.

Noutro ângulo, também são aprofundados os postulados contrários à concentração de poder monárquico em bases de um direito divino com a concessão de poder de modo direto à figura do rei por parte de Deus, e é também demarcado um sutil reforço ao poder

8 Com interessantes impactos na casuística que pretendemos analisar no presente trabalho, conforme buscaremos detida
abordagem
nos 
do papado, ainda que na manutenção do destaque de sua prioritária vocação para questões de fundo espiritual. ${ }^{9}$

Por todos os eventos políticos citados anteriormente, entendemos a influência do tempo histórico vivenciado por esses autores sobre as suas obras e ensino. Portanto, a tradição tomista seria enriquecida com novas percepções e inclinações em natural resposta aos ventos de renovação que o próprio período se encarregava de exigir.

Nessa segunda etapa, as perspectivas estavam abertas a uma ênfase que acabaria por considerar de maneira mais acentuada a importância da ação da vontade nos círculos da lei humana. ${ }^{10}$

Essa percepção caminharia para o reconhecimento de um direito natural relacionado com adaptações às circunstâncias factuais, levando em consideração sua possível contingência espacial e temporal. Algumas análises sobre período, como aquela estabelecida por Cabral de Moncada (1949, p. 69), enxergam em questões dessa natureza os elementos mais tarde aproveitados pelo futuro pensamento jusracionalista gestado e desenvolvido nas centúrias posteriores.

A concepção de poder relacionada com essa segunda fase da Escola Peninsular está relacionada com o entendimento dos autores jesuítas acerca das justificações para a concentração das forças políticas no modelo absolutista, daí a acentuação popular ser a marca das tentativas de diminuição das pretensões reais que faziam frente aos próprios interesses eclesiásticos.

Apesar disso, seguindo a mesma linha dos autores da primeira fase do pensamento peninsular, também não é colocada nas mãos do papado a concentração de poder conforme a defesa das antigas teses hierocráticas. Contudo, mantinha-se preservada tanto uma filiação à linhagem tomista ao mesmo tempo em que seguiam intocadas as diretrizes políticas do papado, uma vez que estes novos escolásticos também esclareciam sua rejeição à ideia de sobreposição entre elementos temporais e espirituais, por parte do rei.

Bastante conhecida foi a reação católica à doutrina estabelecida por Jaime I, monarca que, por via teológica, lançava-se na defesa de seus interesses políticos, posto

\footnotetext{
9 Sobre esse tema, destacamos como referência para o período a obra de Suárez "Defensio Fidei catholicae et Apostotolicae."

10 Ou seja, a lei entendida como producto direto na vontade humana, considerando as implicações de um afastamento dos postulados Tomistas a maneira do que os pensadores nominalistas já haviam considerado.
} 
que, com a elaboração de sua "Apologia do juramento de fidelidade", buscava a chefia dos súbditos na ordem secular e religiosa. ${ }^{11}$

A condenação aos propósitos de Jaime I não tardaria, sobretudo através do Cardeal Belarmino, reconhecido como formulador da concepção de um poder indireto, a entender da possibilidade de interferência temporal papal sujeita à manutenção dos interesses eclesiásticos $^{12}$. Em sequência, uma “obra-resposta" requisitada pelo Papa Paulo V a Francisco Suárez (Defensio Fidei Catholicae et Apostolicae) veio combater ponto a ponto as ideias monarcófilas defendidas pelo soberano inglês.

De toda sorte, mantinham-se as prerrogativas papais quanto à transmissão de seus poderes espirituais por parte de Deus, valendo lembrar o destaque para a possibilidade, ainda que restrita, de sua interferência em questões temporais, ou seja, fugia-se de qualquer entendimento de supremacia absoluta, mas mantinha-se a prerrogativa de uma superioridade espiritual, fim último de todas as realidades políticas, embora já consideradas em círculos distintos e diversos, mas não incomunicáveis. ${ }^{13}$

Para além de Suárez, Luiz de Molina, Lente de prima em Cânones na Universidade de Évora, encontramos as marcantes reflexões jesuítas que presidiram os escritos desta segunda etapa do escolasticismo. Molina é, inclusive, apontado por muitos como um dos pais da concepção de uma "ciência média", entendida como ponto de equilíbrio entre as posturas excessivamente voltadas à defesa do livre-arbítrio e aquelas radicalmente relacionadas com um determinismo.

Outros autores ainda podem ser elencados como naturais partícipes dessa segunda etapa de renovação das ideias tomistas, mesmo aqueles não pertencentes à Companhia de Jesus como é o caso do Frei Serafim de Freitas ${ }^{14}$, doutor em Cânones pela Universidade de Coimbra que elaborou sua importante contribuição através da obra De iusto império Luistanorum Asiatico, obra publicada em território espanhol em 1624 e em Portugal no ano seguinte.

\footnotetext{
11 Com o surgimento da obra encomendada pelo monarca no ano de 1608, discutia-se também a não interferência de uma determinação pontifícia nos vínculos entre os súbditos e o rei, uma vez que a possibilidade de interferências dessa natureza por ocasião do decreto de excomunhão à figura do monarca estava, nessa linha, expressamente fora de questão.

12

12 Jaime I ainda viria a patrocinar a divulgação de uma réplica à condenação de suas teses através da reedição da "Apologia" acrescida do contra-ataque às posições de Belarmino. O Cardeal, ao seu turno, novamente se posicionaria sobre o tema através da obra "De potestate summi pontificis in rebus temporalibus".

${ }^{13}$ Digno de nota a tradição que podemos retomar às ideias do Cardeal Belarmino quanto ao clamado "poder indireto" que estabelecia a possibilidade de interferência em assuntos temporais na medida em fossem ameaçados os interesses espirituais próprio às preocupações do chefe da igreja Universal.

14 Além do citado frei mercedário, podemos também nos referir a outras personalidades como as de Diego de Covarrubias e Vazquez de Menchada como autores que contribuíram para o desenvolvimento das ideias neoescolásticas dessa etapa.
} 
Interessante o conhecimento por parte de Hugo Grócio, já no ano de 1617, de que existia na Espanha um escrito de refutação ao seu Mare Liberum. Segundo Marcelo Caetano, em suas palavras introdutórias à edição da obra de Freitas, a questão poderia sinalizar, com grande probabilidade, que Grócio estivesse a se referir ao livro do Frei Serafim $(1959$, p.40).

Traçadas essas linhas, ainda que breves, sobre os alicerces do pensamento fundamentador da Segunda Escolástica, levando em consideração as ênfases próprias a cada uma das fases desse amplo movimento, direcionaremos, daqui por diante, o nosso olhar para as repercussões dessas ideias nos domínios universitários portugueses, em específico, para um caso até então pouco abordados pelos habituais apontamentos relacionados à escolástica renascida no século XVI.

\section{CONCEPÇÕES JURÍDICO-POLÍTICAS NA CÁTEDRA DO DOUTOR NAVARRO}

No ano de 1538, Dom João III requisita a Carlos V o envio do Doutor Navarro a Portugal para que participasse do estabelecimento da Universidade recentemente transferida de Lisboa para Coimbra.

Aquiescendo às influências políticas determinantes de seu deslocamento dos domínios de Espanha, segue Navarro para Portugal transferindo-se com um dos melhores soldos destinados à atividade docente e as mesmas prerrogativas de lente em cânones que envergava em Salamanca.

Digno de nota o facto registrado por Navarro no seu comentário "in cap; Inter verba", sobre o seu pedido para que D. João III não permitisse o provimento das cadeiras da universidade, recém-transferida para Coimbra, da forma como era levada a cabo em Salamanca, ou seja, num sistema em que as cadeiras podiam ser alienadas livremente (FERREIRA, 1938, p. 455). Tal pedido, plenamente aceito e seguido demonstra o bom transito político e o relevo atribuído à opinião de Navarro na gestão dos assuntos acadêmicos.

Contudo, para entendermos o desenvolvimento de suas ideias e as naturais vinculações com os grandes teóricos que inspiraram a sua cátedra, imprescindível visualizarmos as etapas iniciais da formação acadêmica.

15 A universidade de Toulouse destacava-se, nesse período, como uma das mais prestigiadas em França. 
Inicialmente estudante da Universidade de Alcalá, onde permaneceu entre os anos de 1503 e 1510, buscou transferência para a Universidade de Toulouse $^{15}$. Sua carreira docente, teve início ainda em território francês já no domínio dos Cânones nas Universidades de Cahos e na de Toulouse, instituição na qual ensinou direito canónico e civil e adquiriu a titulação de "Doutor". Conforme a transcrição e tradução de José Manuel Pérez Prendez, para o espanhol, Navarro (1965, p. XLIII)., em sua Carta Apológética, discorre sobre sua formação em território francês assim se expressando: "blasono y me alegro muchísimo de ello, de Haber estudiado y enseñado Derecho canónico y civil durante largo tiempo em Francia".

No ano de 1520, naquela mesma instituição, defendeu a dissertação por ele intitulada como "pacífica". Contado apenas com a idade de vinte e oito anos, tratou nessa sua "Repetição", segundo os apontamentos de Francisco Ferreira Leitão (1938, p.188-189), de mostrar que mostrar, que ninguém, "por ser daquela cidade, ou sendo nela estrangeiro, ou da mesma Nação Francesa, ou de qualquer outra, mas só por amar a virtude, ou aborrecê-la, devia ser mais, ou menos bem visto dos seus próximos".

Sobre essa época de formação e docência em França, digno de nota o convite feito para o exercício do cargo de conselheiro da prefeitura de Paris. Findo esse período, de retorno à Espanha, ingressa na Universidade de Salamanca e assume, em regime de suplência, a cátedra de prima em Cânones, então regida pelo Doutor Tapia. Em sequencia ministra aulas em uma cátedra menor em Cânones, a cadeira de Decreto e, logo a seguir, a de Prima em Cânones em 1537, regência que ocuparia pelos catorze anos seguintes.

Em Salamanca procura empreender um método diferenciado de ensino com a aplicação conjunta dos elementos teologia moral, direto civil e direito canônico além da realização de aulas extraordinárias de filosofia jurídica. Essa abordagem de Navarro garantiu o reconhecimento tanto dos demais catedráticos como dos alunos, pois suas aulas chegavam a abarcar o número de mil pessoas, tamanho o reconhecimento que amealhara.

Sobre essa fase da carreira, chegaria a afirmar que sua contribuição ao brilho da instituição salmantina, na área de Cânones, chegava a se comparar com aquela produzida pela atuação de destacados professores também de formação francesa, como João Martinho Siliceo e o mais elevado expoente do período: Francisco de Vitoria. 
$\mathrm{Na}$ sua carta apologética dirigida ao Duque de Albuquerque registrou Navarro as suas impressões sobre esse período de mudança para Salamanca e o significado de sua permanência naquela instituição ${ }^{16}$ nos seguintes termos:

Nadie niega que yo traje desde Tolosa, en Francia, a la universidad de Salamanca (la más antigua de Castilla la Vieja y la principal entre todas las del mundo cristiano) uma ciência sólida u útil del Derecho Canónico. Del mismo modo, um año después, Fray Francisco de Vitoria, tão sábio como piadoso, introdujo uma elaborada Teologia, estudiada em la Universidad de París. (NAVARRO,1965, p.XLIII)

Interessante, nesse tópico, atentarmos para o juízo elaborado por Navarro no tocante a sua própria importância e na comparação com nomes de destaque no universo salmantino do período, no qual se destaca Francisco de Vitória. Navarro, apesar de estabelecido anteriormente à presença de Vitória em Salamanca ${ }^{17}$, não se distanciou do magnetismo das ideias defendidas e difundidas por ele.

No destaque de sua vinculação aos postulados defendidos pelo próprio Vitória, o Doutor Navarro chegou a exaltar as qualidades do seu colega docente quando considerou que:

\begin{abstract}
"Nadie niega que yo traje desde Tolosa, em Francia, a la Universidad de Salamanca (la más antigua de Castilla la Vieja y la principal entre todas las del mundo cristiano) uma ciencia sólida u útil del Derecho Canónico. Del mismo modo, um año después, Fray Francisco de Vitoria, tan sábio como piadoso, introdujo uma elaborada Teología, estudiada em la Universidad de París". (NAVARRO,1965, p.XLIII)
\end{abstract}

Ao comentar os traços dessa influência Alonso Getino (1914, p.139), em estudo específico sobre Francisco de Vitória e o pensamento filosófico do período, apontou para o entendimento de que Navarro poderia ser visto como um "companheiro de ensino que se amoldou ao espírito de Vitória”. Para o citado comentarista da obra de Vitória, Navarro seria "um moralista consumado que nos fala da maneira de ensinar moral de Vitória" e que busca definir esse mesmo ensino como "superior a todos os seus antecessores" facto que indicaria que Navarro comparava suas próprias lições às de Vitória e nelas se inspirava.

Já na Universidade de Coimbra, as marcas fundamentais do pensamento jurídicoteológico de Navarro e o traço de sua filiação às origens do pensamento peninsular jusnaturalista desenvolvido em Salamanca, podem ser observadas com a devida clareza no

\footnotetext{
16 Também se refere ao mesmo período em outros documentos, como na Repetição ao Capitulo "Inter verba XI. quaest. 3" e na prefação aos Commentarios, sobre as sete distinçoes "de Paenitenciã".

17 Cerca de um ano antes, conforme os apontamentos do "De reditibus", q. Ia, 52. Navarro, de fato, inicia em regime de suplência ao doutor Tapia na cátedra de prima em Cânones.
} 
seu desenvolvimento do seu magistério em Coimbra. Ainda é digna de nota a referência de uma relação defendida por Navarro junto ao pleno da Universidade no ano de 1548 , em que postulou ideias marcadas pelas reflexões de Vitória.

A citada relação pronunciada por Navarro (NAVARRO.1965, p. X) "assinala um dos momentos mais importantes da elaboração da doutrina espanhola da paz." Pois nela temas como sociedade e pessoa humana, formas de associação, príncipe e cidadão, o poder do papado e do Império, Igreja e Estado, nação e comunidade internacional são o esquema de Francisco de Vitória que Martín de Azpilcueta completa e atualiza.

Nessa ocasião, Navarro teve a oportunidade de explanar, nas mesmas linhas vitorianas, sobre uma possível confederação europeia no resguardo de sua unidade cultural; o papado visto como um poder do tipo moderador; a criação de um exército europeu comum (relacionado com as regiões cristãs) e ainda teceu considerações acerca das relações internacionais. (PERENÃ.1986, p.59)

Nas ideias do Doutor Navarro, encontramos a marca dos temas jurídico-teológicos próprios às preocupações peninsulares do período e que despontavam na cátedra dos autores relacionados à segunda escolástica, principiando por Francisco Vitória. Portanto, aos traços característicos de sua filiação aos estudos canónicos, é possível enxergar uma natural abertura aos novos horizontes temáticos dos descobrimentos marítimos e das inovações sociais a ele relacionadas.

Algumas das principais ideias defendidas por Navarro e comuns aos principais teóricos desse momento histórico dizem respeito à concepção de poder visto em sua origem democrática, a separação e influência limitada entre o poder religioso e civil, bem como considerações relacionadas com o conceito e requisitos para a ocorrência da chamada "guerra justa".

Noutro sentido, o canonista também soube equacionar, em outras obras, temas essencialmente ligados às questões morais com repercussão, inclusive, para a área económica. No seu "Comentario Resolutorio de Cambios", tratou sobre a disciplina moral ligada a este setor da vida humana, tanto nas relações intersubjetivas nacionais quanto entre indivíduos no âmbito de circulação econômica internacional.

As questões de pertinência ética foram desenvolvidas, sobretudo, na sua obra de maior repercussão, o "Manual de Confessores e Penitentes", trabalho redigido ao estilo dos manuais morais que tanto marcaram a realidade histórica em comento, e no "Comentário 
Resolutório de Câmbios", traço de filiação do autor à escola econômica ibérica própria ao século XVI.

António Pedro Barbas Homem (1988, p.164), em comentário sobre a ênfase da teologia moral para a formação teórica e as atividades práticas dos profissionais do direito do período, como exemplificação a esta etapa histórica apontou para as ideias do Navarro, constantes em seu manual, a respeito do pecado cometido pelos advogados e procuradores que, no exercício da profissão, advogassem em causa injusta carecendo de estudo jurídico prévio e agissem com notável negligência e ignorância. Para Navarro, ocorrências dessa natureza ensejariam ainda a obrigação, por parte desses profissionais, de restituir os danos causados (se a parte ignorava a não justeza da causa).

Contudo, sobre a gênese das ideas desenvolvidas pelo Doutor Navarro quanto ao tema da origem democrática do poder, observamos que o próprio professor fez questão de registrar em suas memórias aquilo que considerou como um momento marcante em sua trajetória teórica: a defesa de suas ideias diante de Carlos V, por ocasião da visita do Imperador à cidade de Salamanca.

O canonista, naquela oportunidade, foi capaz de apontar diante da representação imperial a sua concepção de poder que seria repetida, anos mais tarde, diate do Pleno da Universidade de Coimbra. Suas concepções destacavam que o reino não pertencia ao Rei e sim à comunidade. Dessa forma, o poder real residiria na própria comunidade por direito natural e não na figura do Rei, concepção diametralmente oposta àquela sustentada pelos teóricos de um poder diretamente emanado por Deus em benefício do soberano.

No ponto de vista defendido por Navarro, a autoridade deveria ser entendida como uma concessão da divindade estabelecida de maneira imediata. Nesse caso, o poder pertenceria à comunidade por ser a ela inerente, ou seja, experimentado como realidade natural oriunda da própria natureza societária humana.

Assim, as organizações políticas temporais estariam justificadas pela natureza da sociedade humana, uma vez criada por Deus com a clara necessidade de organização. Há aqui, portanto, a concepção de que o soberano não seria objeto de uma legitimação especial proveniente da divindade, mas sim da própria comunidade.

Em outro tópico sobre o entendimento do poder, Navarro ainda estabelece que os traços distintivos entre o poder espiritual e civil, delimitando a possibilidade de ingerência do primeiro sobre o segundo. No mesmo esteio dos demais autores escolásticos do período, a começar por Francisco Vitória, há um afastamento de um absoluto ponto de vista 
hierocrático a partir do momento em que uma intervenção da autoridade do Papa, em questões próprias ao poder civil, é vista como possibilidade restrita à presença de uma devida justificativa sinalizadora de um gravame a ordem espiritual através do abuso cometido pelo poder temporal.

Por esta percepção o âmbito político papal teria uma potestade direta sobre os assuntos propriamente religiosos e uma potestade indireta sobre os assuntos temporais. Potestade indireta e, portanto, restrita à ocorrência de uma "contaminação" espiritual pela nefasta ingerência do poder civil, facultando a atuação papal nessa outra esfera política, seja na elaboração de normas ou na determinação de uma não observância daquelas emanadas pelos príncipes, quando das circunstâncias ora citadas.

O ponto de vista hierocrático, interpretado de maneira alargada, daria amplas possibilidades à autoridade religiosa a atuar junto aos súditos ligados ao príncipe que ficariam livres dos vínculos políticos com ele estabelecidos no momento de sua ruptura com as determinações papais. O ponto de vista da potestade indireta, contudo, busca resguardar o âmbito de ação do poder papal prioritariamente no âmbito religioso e, quando da ocorrência de uma intromissão do temporal sobre os assuntos espirituais, a interferência do segundo sobre o primeiro de maneira justificada e sempre vista como indireta.

Merece ainda menção a natural concepção de que o poder papal, distinto em seu âmbito de ação prioritariamente espiritual e indiretamente temporal, teria como clara exceção o poder exercido de maneira direta sobre os chamados Estados Pontifícios, conforme a peculiaridade política vivida no panorama italiano da época. Contudo, fora dos limites do domínio do Papa sobre essas regiões tradicionalmente ligadas à sua esfera temporal, vigorava claramente, para Navarro, a tese do poder indireto no que diz respeito à ingerência sobre as realidades civis.

Diante desses entendimentos sobre o poder é que podemos enquadrar o tratamento, dado por Navarro no que diz respeito ao "direito das gentes", uma vez que para o autor todos os povos deveriam ser vistos como titulares da possibilidade de autogoverno. Essa ideia de autonomia conferida aos povos, independente de sua vinculação ao cristianismo, viria a contrapor o pensamento de Navarro à proposição de que aqueles grupamentos qualificados como pagãos estariam desprovidos de governança civil reconhecível e, por conseguinte, submetidos à autoridade da Igreja.

Essa percepção é claramente lastreada pela diferenciação, já aqui abordada, entre poder temporal e poder espiritual, mas conjugada ao raciocínio de que existiriam parcelas 
da cristandade não situadas em regiões do império tradicionalmente estabelecido no ocidente, ou seja, não ligadas ao legado romano e ao próprio cristianismo. Noutro sentido, também atuando como elemento fundamentador desse ponto e vista, há o reconhecimento de que em territórios imperiais do ocidente cristão estariam, de igual forma, vinculados ao poder políticos indivíduos não necessariamente cristãos.

Tudo, nessa questão, contribui para a elaboração teórica defendida por Navarro uma vez que, ao reconhecer a autonomia política dos povos, sejam eles cristãos ou não, qualquer intervenção bélica a eles relacionada deveria estar resguardada pela observação de certos elementos, quais sejam: o reconhecimento de uma causa justa (daí a titulação de "guerra justa") seja a busca pela reparação danos perpetrados, o atentado às questões religiosas, para sustentar a própria defesa ou mesmo dos seus. Como segundo horizonte de causas permissivas da guerra, vista como justa, somada às possibilidades das ocorrências elencadas encontramos a necessidade de uma reta intenção como justificativa para esse esforço.

Contudo, presente se encontra a consideração das motivações religiosas como ensejo para a justeza dos esforços de guerra, traço que expõe o centralismo das questões canônicas presentes na defesa aguerrida dos pressupostos católico-romanos em época marcada pela reação à reforma protestante,

Navarro em seu "De Tregua et Pace", presentemente traduzido para o espanhol e comentado por Maria Luisa e José Olarra (1963, p.95), manifesta entendimento contrário à resolução do conflito entre Carlos IX e os protestantes, por ocasião da chamada "Paz de Saint- Germain" no ano de 1570. Navarro defendia a possibilidade do manejo de uma guerra absolutamente justa uma vez que, segundo o seu ponto de vista, o motivo residiria uma quebra da lei natural pela ocorrência da própria heresia. Não obstante, Navarro entendia que os príncipes deveriam buscar aconselhar-se com homens moralmente razoáveis, ou seja, sábios e livres de ódio ou ira e, além disso, buscar a escuta do adversário quanto às suas razões. 


\section{CONSIDERAÇÕES FINAIS}

O univero que o presente artigo se esforçou em delimitar, aqui foi exposto como como uma das primeiras manifestações da segunda escolástica no ambiente acadêmico lusitano que, embora posteriormente desdobrando em temáticas diversificadas, apresentava uma natual vinculação de continuidade com os pontos de vista próprios ao território espanhol.

Tópico interessante é a completa inclusão do entendimento de Navarro acerca dos problemas da dominação dos povos indígenas pelas potências europeias quando, afastando o traço de justificação religiosa para o domínio desses povos em razão de uma possível evangelização, compartilha integralmente do que expôs a Escola de Salamanca quanto ao tema. Assim, Navarro caminha nas mesmas bases que Vitória e os outros doutores espanhóis no que toca ao direito dos habitantes do novo mundo defenderem os seus territórios, salvo na ocorrência de motivações essências para a fundamentação de uma guerra justa.

Muito além dos clássicos temas moralizantes lançados quer seja sobre a temática econômica ou sobre o amplo tratado ético que a sua "ciência canônica" tornaria célebre, a contribuição do Doutor Navarro aponta para o clara defesa dos postulados da "Escola de Salanca" quando do seu envino em ambiente lusitano. Representa, assim, a marca do traço de união entre os mestres de Salamanca com aquilo que seria estabelecido na Universidade de Coimbra por variadas figuras que, ao representarem uma segunda etapa do desenvolvimento dos postulados da escolástica renovada, caminhariam ainda por outras sendas sem decuidar dos postulados fundamentais já defendidos em território lusitano.

Fica aqui o registro da percepção de uma autonomia política dos povos, fato que desembocará nas acentuadas discussões do período que se voltaram para a sorte dos indígenas quando das pretensões imperialistas dos reinos peninsulares que tanto marcaram o ponto de vista universitário desde Bartolomé de las Casas, Vitória, e os demais autores da segunda escolástica, inclusive estabelecidos em território português. 


\section{REFERÊNCIAS BIBLIOGRÁFICAS}

ALBUQUERQUE, Martim de. Aspectos políticos da obra de Molina in Luís de Molina Regressa à Évora - Actas das Jornadas, organização Irene Borges Duarte. Évora, Fundação Luis de Molina, 1998.

Contributo Português para a obra de Althusius. Estudos políticos e sociais. Lisboa: Instituto Superior de Ciências Sociais e Política Ultramarinha, V. VIII, nº 4, 1969.

Nacional-Casa da Moeda.V. 3. 1983.

Estudos de Cultura Portuguesa. Lisboa: Imprensa

Jean Bodin en la Peninsula Ibérica. Tese de doutoramento apresentada na Faculdade de Direito da Universidade Complutense. Madrid: Universidad Complutense, 1976.

O Poder Político no Renascimento Português. Lisboa: Instituto Superior de Ciências Sociais e Política Ultramarina. [s.d].

AQUINO,Tomás de. De Regno. Petrópolis: Editora Vozes, 1997.

CAlAFATE, Pedro. História do Pensamento Filosófico Português. Lisboa: Caminho. V.II. 2001.

CAETANO, Marcello. Recepção e execução dos decretos do Concílio de Trento em Portugal. Lisboa: Revista da faculdade de Direito da Universidade de Lisboa, V. XIX, 1965.

COSTA, Mário Júlio de Almeida. História do Direito Português. Coimbra: Almedina. 2002.

FERNÁNDEZ, Rafael Pardo. Martín de Azpilcueta y su época. Pamplona, Gobierno de Navarra, 2011.

FERREIRA, Francisco Leitão. Notícias Chronologicas da Universidade de Coimbra. Segunda parte, Vol. I, Coimbra: Universidade de Coimbra. 1938.

FRANCO, Imagem da Virtude em o Noviciado da Companhia de Jesus no Real Collegio de Coimbra. Coimbra, II, 1719.

FREITAS. Frei Serafim de. Do Justo Império Asiático dos Portugueses. Lisboa: Instituto de Alta cultura. V.I. 1959.

GETINO, Fr. Luiz G. Alonso. El maestro F. Francisco de Vitória y el renacimiento filosófico teológico del siglo XVI. Madrid: Tip de la Revista de Archivos. 1914.

GROSSI, Paolo. La Seconda Scolastica nella Formazione del Diritto Privato Moderno. Milano: Giuffré Editore. 1972. 
HEREDIA, R. P. Vicente Beltrán de. Domingo de Soto - Estudio biográfico documentado. Madrid: Ediciones Cultura Hispanica: 1961.

S. A. 1939.

Francisco de Vitória. Barcelona: Editorial Labor,

MARTINS. José V. de Pina. Humanismo e Erasmismo na Cultura Portuguesa do século XVI. Paris: Fundação Calouste Gulbenkian. 1973.

MEREAA, Paulo. Sobre a origem do poder civil: Estudos sobre o pensamento político e jurídico dos séculos XVI e XVII. Coimbra: Tenácitas. [s.d].

MONCADA, Luís Cabral de. O vivo e o morto em Suarez jurista, Lisboa: Boletim do Ministério da Justiça, 1949, nº 9, p.69.

NAVARRO, Martin de Azpilcueta. Commentario Resolutorio de Cambios. Madrid: Consejo Superior de Investigaciones Cientificas. 1965. P. XVI. Superior de Investigaciones Cientificas. 1965. p. XLIII.

OLARRA, Maria Luisa. OLARRA, Jóse. Miscelánea de noticias romanas acerca de Don Martin de Azpilcueta, Doctor Navarro. Madrid: Espasa-Calpe, 1943.

PATRÍCIO, Manuel Ferreira. A doutrina da "ciência média": de Pedro Fonsca e Luís de Molina in Luís de Molina regressa á Évora. Évora:Fundação Luís de Molina. 1998. P.165.

PEREÑA, Luciano. La Escuela de Salamanca. Proceso a la conquista de America. Salamanca: Ediciones de la Caja de Ahorros Y M. de P. de Salamanca. 1986.

RAMAlHO, Américo da Costa. Para a História do Humanismo em Portugal. Lisboa, Imprensa nacional casa da moeda. 1998. V.1. p.176.

SEIXAS, Margarida. Segunda Escolástica e Restauração: Contributo para o estudo da influência da Escola Peninsular na justificação político-jurídica restauracionista. Tese de mestrado apresentada na Faculdade de Direito da Universidade de Lisboa. Lisboa: Universidade de Lisboa, 1999.

SKINNER, Quentin. Visões da Política. Questões Metodológicas, Lisboa: Difel. 2005. p.165.

TRELLES, Camilo Barcia. Interpretacion del Hecho Americano por la España Universitária del Siglo XVI. Montevideo: Instituicion Cultural Española del Uruguay. 1949.

TRUYOL Y SERRA. António. História do Direito Internacional Público. Lisboa: Instituto Superior de Novas Profissões, 1995. 